SISTEMA
ELETRONNICO
DE REVISTAS
SER I UFPR

\title{
Mudanças socioeconômicas e ambientais resultantes das políticas públicas de desenvolvimento socioeconômico no litoral do Nordeste do Pará, Brasil
}

\section{Changes socioeconomic and environmental result of public policies socioeconomic development in the northeast coast of Pará, Brazil}

\author{
Adrielson Furtado ALMEIDA ${ }^{1 *}$, Mario Augusto Gonçalves JARDIM ${ }^{2}$ \\ ${ }^{1}$ Programa de Pós-Graduação em Ciências Ambientais, Universidade Federal do Pará (UFPA), Belém, PA, Brasil. \\ ${ }^{2}$ Museu Paraense Emílio Goeldi, Belém, PA, Brasil. \\ *E-mail de contato: adrielsonfurtado@gmail.com
}

Artigo recebido em 8 de setembro de 2017, versão final aceita em 23 de novembro de 2018.

RESUMO: A partir da segunda metade do século XX, territórios praieiros de domínio das populações pesqueiras na zona costeira do Nordeste do Estado do Pará, passaram a receber políticas públicas para o desenvolvimento socioeconômico. Gerando forte antropia na relação entre os aspectos socioeconômicos e ambientais. Este estudo objetivou analisar as principais mudanças socioeconômicas e ambientais resultantes dos investimentos públicos em expansão rodoviária, urbanização e turismo balnear nas praias do Atalaia (Salinópolis), Ajuruteua (Bragança) e Crispim (Marapanim), a partir de 1960. O método contou com revisão bibliográfica, seleção das áreas de riscos na costa Atlântica paraense, visitas in loco, 115 entrevistas pessoais (exploratório e descritivo) e análise dos dados. Os resultados indicaram como mudança ambiental a substituição da vegetação e dunas para edificações civis (Q.3 - campos entre dunas: 61,8\%; dunas: 21,7\%; mangue: 11,3\%; Q.7 - comércio/ serviços: $66,1 \%$; $2^{\circ}$ residência: $17,40 \%$; residência: $16,5 \%$ ). No social, houve a substituição dos espaços de pesca para urbanização turística (Q.2 - comprado: 47\% e ocupado: 40,9\%). No econômico houve a substituição das atividades de pesca tradicional para atividade turística (Q.7 - comércio/serviços: $66,1 \%$ e extrativismo animal: $0 \%$ ). Os impactos negativos gerados têm implicação com a falta de infraestrutura urbana (Q.8 - ausência de serviços públicos: 72,3\%), recuo da linha de costa (Q.8 - erosão costeira: 17,4\%), e a má qualidade da prestação dos serviços de apoio atividade turística (Q.9 - prestação de serviços: 52,2\%). Conclui-se que as situações problemáticas atuais (poluição ambiental, erosão costeira, deficiência da oferta e serviços turísticos) são consequências do processo de ocupação e formação socioespacial desenvolvida pelo poder público, que para gerar o desenvolvimento socioeconômico desconsiderou os ordenamentos jurídicos de preservação da orla marítima, promovendo a expansão urbana e o desenvolvimento do turismo balnear, 
sem planejamento e infraestrutura adequada, gerando impactos negativos que dificultam o desenvolvimento socioeconômico da região.

Palavras-chave: políticas públicas; municípios costeiros; praias.

ABSTRACT: From the second half of the twentieth century, the prairie territories of the fishing communities in the coastal zone of the State of Pará Northeast began to receive public policies for socioeconomic development. Generating strong anthropy in the relationship between socioeconomic and environmental aspects. This study aimed at analyzing the main socioeconomic and environmental changes resulting from public investments in road expansion, urbanization and beach tourism on the beaches of Atalaia (Salinópolis), Ajuruteua (Bragança) and Crispim (Marapanim), beginning in 1960. The method was reviewed bibliography, selection of risk areas on the Atlantic coast of Pará, on-site visits, 115 personal interviews (exploratory and descriptive) and data analysis. The results indicated as environmental change the replacement of vegetation and dunes for civilian buildings (Q.3 - fields between dunes: $61.8 \%$, dunes: $21.7 \%$, mangrove: $11.3 \%$, Q.7 - trade / services: $66.1 \%$, 2nd residence: $17.40 \%$, residence: $16.5 \%$ ). In the social area, there was a replacement of fishing spaces for tourism urbanization (Q.2 - purchased: $47 \%$ and occupied: $40.9 \%$ ). In the economy there was a substitution of traditional fishing activities for tourism (Q.7 - trade/services: $66.1 \%$ and animal extractivism: $0 \%$ ). The negative impacts generated have implications on the lack of urban infrastructure (Q.8 - lack of public services: $72.3 \%$ ), coastline retreat (Q.8 - coastal erosion: $17.4 \%$ ), and poor service provision quality to support tourist activity (Q.9 - service provision: $52.2 \%$ ). It is concluded that the current problematic situations (environmental pollution, coastal erosion, supply deficiency and tourist services) are consequences of the socio-spatial occupation and formation process developed by the public power, which, in order to generate socioeconomic development, disregarded the legal systems for preserving the border promoting urban expansion and the development of bathing tourism, without planed and adequate infrastructure, generating negative impacts that hinder the socioeconomic development of the region.

Keywords: public policies; coastal municipalities; beaches.

\section{Introdução}

A formação da organização socioespacial da zona costeira do Nordeste do Pará inicia-se por volta de 5.000 anos antes do presente (AP), quando as características da região (elevada produtividade, biodiversidade e disponibilidade de alimentos) permitiram a sedentarização de grupos humanos que sobreviveram primariamente de recursos do mar e do mangue (Silveira \& Schan, 2010). Estes grupos denominados de pescadores-coletores e caçadores formaram ocupações relativamente densas e permanentes em áreas não alagáveis junto aos manguezais do litoral paraense até $3.000 \mathrm{AP}$, comprovados por sítios arqueológicos (sambaquis litorâneos) e, descritos por viajantes e naturalistas do século XVIII e XIX (Ferreira Penna, 1876; Simões, 1981; Silveira et al., 2011).

No século XVII, os remanescentes destes grupos pré-históricos, denominados de índios Tupinambás pelos colonizadores portugueses, possuíam certa organização sócio-espacial e conhecimento acerca do ambiente costeiro para a sua reprodução social (caça, extrativismo, roça, pesca e produção de sal para a salga de peixe) (Furtado, 2013). A política colonial portuguesa, visando o progresso 
e o povoamento do litoral amazônico, promoveu a reorganização socioeconômica do espaço (1645), com a inserção do trabalho indígena nas relações econômicas capitalistas, no trabalho político-militar de atalaia e de praticagem da barra (Almeida, 2017).

Do século XVII ao final do século XIX, a política da metrópole portuguesa, e mais tarde da imperial, era de viabilizar ao longo da costa pequenos portos seguros para baldeações das rotas de navegação fluvio-marítimas entre Belém e São Luís (Furtado, 2013). As pequenas unidades sociais pela orla marítima tornaram-se povoados, ganharam foros de freguesia, sendo posteriormente elevada à categoria de vila, município e cidade, funcionando como centro catalizador e distribuidor da produção pesqueira e agrícola; os recursos pesqueiros garantiram a sustentação socioeconômica e o progresso das unidades sociais, promovendo a ocupação humana do litoral amazônico (Furtado, 1981; 2002; 2013).

No período em que a Amazônia iniciou um processo de povoamento regional impulsionado pela cadeia produtiva da economia da borracha (1870-1912), houve uma revolução socioeconômica nas cidades de Belém e Manaus, enquanto a maioria das cidades costeiras não acompanharam tais transformações, caracterizando-se como pequenos povoados de pescadores artesanais (Meirelles Filho, 2006; Becker, 2008). Somente algumas cidades litorâneas (Bragança e Salinópolis) passaram gradativamente por inovações (telégrafos sem fio, luz elétrica, aberturas de estradas e ferrovias) e mudanças urbanísticas, como reflexo da evolução social diante da formação socioeconômica capitalista no Brasil, no início do século XX (Almeida, 2015).

Na segunda metade do século XX, a Amazônia foi inserida no modelo desenvolvimentista do presidente Juscelino Kubitscheck (1956-1960), através do investimento em políticas públicas no setor de transporte (criação da rodovia Belém-Brasília (BR-010)), tendo continuidade durante o regime militar (1964-1985), por meio de um sistema de planejamento centralizado nas decisões e metas econômicas, visando o desenvolvimento socioeconômico, integração nacional, colonização como parte integrante da reforma agrária e a inserção da Amazônia na econômica nacional (Becker, 2009; Arend \& Fonseca, 2012).

Dentre as políticas desenvolvimentistas, o turismo como atividade econômica passou a ser regulamentada pelo poder público a partir da criação da Empresa Brasileira de Turismo - Embratur (1966), dando início ao planejamento da atividade; para a região Norte, a Embratur passou a direcionar ações promocionais, como o projeto "Portões de Entrada" que transformou as cidades de Manaus (AM) e Belém (PA) em destinos de entrada para a região Amazônica (Desde 1959, o Aeroporto Internacional de Belém recebe voos nacionais e internacionais) (Kajihara, 2010; Lohmann \& Panosso Netto, 2008).

A Superintendência de Desenvolvimento da Amazônia - SUDAM (1966) também incentivou o planejamento regional do turismo através da execução dos Planos de Turismo da Amazônia (PTA); bem como a Companhia Paraense de Turismo - Paratur (Lei 4.368/1971) que, a partir da estratégia de diferenciação do produto turístico nacional utilizada pela Embratur, promoveu um aumento da atividade turística nas áreas litorâneas do Estado (Pinto, 2007).

No litoral do NE do Pará, a cidade de Salinópolis é pioneira no turismo balnear regional desde a inauguração do seu primeiro hotel em 1936. No entanto, o seu fluxo turístico ganha impulso após a nomeação do município em Estância Hidromineral 
(Decreto-Lei 3.786/1966) pelo governo Federal, em virtude da existência de uma nascente de água mineral (fonte do Caranã), quando o governo do Estado passou a investir em infraestrutura urbana e, no desenvolvimento do turismo balnear, a exemplo das praias da ilha do Atalaia, que passaram a ter interligação rodoviária (1973) e uma nova estrutura socioespacial (Adrião, 2006; Ranieri \& El-Robrini, 2015; Almeida, 2017).

Seguindo o mesmo modelo de desenvolvimento socioeconômico de Salinópolis, os políticos da cidade de Bragança, almejando o aproveitando das potencialidades turísticas do seu litoral, planejaram a construção da estrada Bragança-Ajuruteua - PA458 (1975-1991), como um prolongamento do projeto rodoviário da Pará-Maranhão (BR-308); em 1987, antes da conclusão da rodovia, o poder público municipal incentivou a urbanização e o aumento do fluxo turístico na praia de Ajuruteua (Fernandes et al., 2007; Almeida, 2017).

Na década de 1990, o litoral Atlântico paraense passou a ter um aumento substancial da atividade turística envolvendo segmentos nacionais e internacionais (Quaresma \& Campos, 2006). O governo do Estado visando ampliar o fluxo turístico (regional) do município de Marapanim (a praia de Marudá movimentava a economia local desde a década de 1960), inaugurou em 1991 a PA-318 (Marudá-Crispim) (Furtado et al., 2006). A rodovia foi construída sobre uma antiga estrada de acesso às vilas de Bacuriteua, Camará e a praia do Crispim, esta deixou a tranquilidade dos seus ranchos de pesca para tornar-se o novo point dos veranistas no mês de julho (férias escolares), passando a demandar serviços turísticos, especulação imobiliária e urbanização (Bastos et al., 2013).
Em virtude dos processos de uso e ocupação ocorridos nestas praias no litoral paraense, estudos foram desenvolvidos buscando analisar seus aspectos socioambientais e econômicos (Costa Neto et al., 2000; Adrião, 2006; Furtado et al., 2006; Pereira et al., 2006; Quaresma \& Campos, 2006; Pinto, 2007; Gregório et al., 2011; Souza Filho, 2013; Ranieri \& El-Robrini, 2015; 2016), contribuindo com o conhecimento para novos meios de desenvolvimento que considere tais aspectos de forma integrada e indissociável. Este estudo objetivou analisar as principais mudanças nos aspectos socioeconômicos e ambientais resultantes dos investimentos públicos em expansão rodoviária, urbanização e atividade turística nas praias do Atalaia (Salinópolis), Ajuruteua (Bragança) e Crispim (Marapanim), no litoral do Nordeste do Pará, a partir de 1960.

\section{Método}

\section{1. Área de estudo}

A zona costeira do Nordeste do Estado do Pará possui $598 \mathrm{~km}$ de extensão (Baía do Marajó - rio Gurupi), distribuídos em 13 municípios costeiros. Para este estudo foram selecionados a praia do Crispim em Marapanim (00³7'06'S, 00³4'42"S e $47^{\circ} 40^{\prime} 24^{\prime \prime} \mathrm{W}, 47^{\circ} 38^{\prime} 00^{\prime \prime} \mathrm{W}$ ) distante $156 \mathrm{~km}$ da cidade de Belém por via rodoviária. A praia do Atalaia em Salinópolis $\left(00^{\circ} 35^{\prime} 22^{\prime \prime} \mathrm{S}, 00^{\circ} 38^{\prime} 43^{\prime \prime} \mathrm{S}\right.$ e $47^{\circ} 15^{\prime} 47^{\prime \prime} \mathrm{W}$ e $47^{\circ} 21^{\prime} 12^{\prime \prime} \mathrm{W}$ ) distante $213 \mathrm{~km}$ da capital paraense e, a praia de Ajuruteua em Bragança $\left(0^{\circ} 48^{\prime} 56^{\prime \prime} \mathrm{S}, 0^{\circ} 50^{\prime} 07^{\prime \prime} \mathrm{S}\right.$ e $46^{\circ} 36^{\prime} 58^{\prime \prime} \mathrm{W}$, $\left.46^{\circ} 36^{\prime \prime} 04^{\prime \prime} \mathrm{W}\right)$, distante $246 \mathrm{~km}$ da capital do Estado (Almeida, 2017). A localização das áreas pode ser vista na Figura 1. 


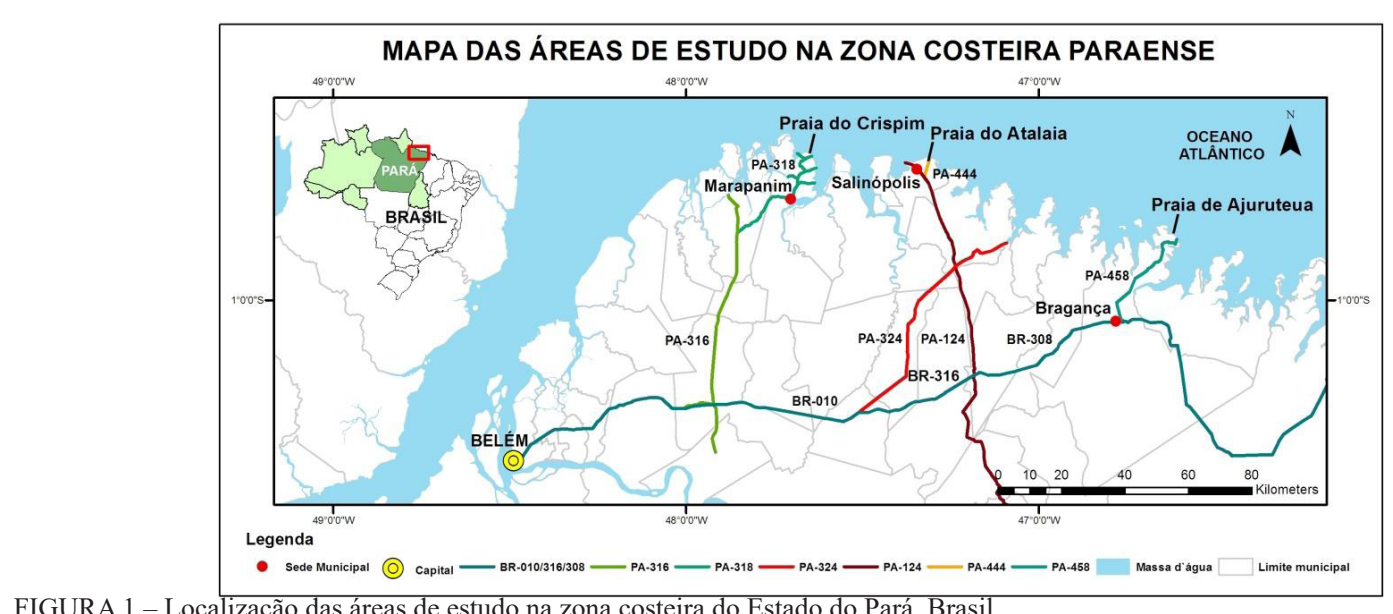

FIGURA 1 - Localização das áreas de estudo na zona costeira do Estado do Pará, Brasil.

FONTE: Elaborado pelos autores.

\subsection{Etapas da pesquisa}

As etapas para o desenvolvimento desta pesquisa contaram com a realização da fundamentação teórica e a descrição dos fatos históricos, que embasaram o desenvolvimento da abordagem cientifica conforme ponderam alguns autores (Lakatos \& Marconi, 2007). Esta etapa foi construída com base na revisão bibliográfica dos seguintes temas: ocupação pré-colonial e colonial da zona costeira paraense e políticas públicas do período colonial até a fase desenvolvimentista/militarista, nestas optou-se por analisar os investimentos públicos nas áreas de transporte, urbanização e turismo, por terem contribuído como vetores do desenvolvimento socioeconômico da zona costeira paraense.

$\mathrm{Na}$ segunda etapa, optou-se pela seleção das áreas de estudo a partir do "Diagnóstico para avaliação e ações prioritárias para conservação da biodiversidade da zona costeira e marinha amazônica" (MMA, 1999), na qual as praias do Atalaia (Salinópolis), Ajuruteua (Bragança) e, Crispim (Marapanim) foram citadas como as principais áreas de riscos na costa Atlântica paraense resultantes dos processos de expansão rodoviária e ocupação urbana.

Na terceira etapa, após a realização da revisão bibliográfica e seleção das áreas de pesquisa, foram realizadas visitas in loco e entrevistas com caráter exploratório e descritivo em três períodos (jul./2013, jul./2014 e mai.-jun./2015). No primeiro período, entrevistaram-se os proprietários (comerciais e residenciais) localizados próximos a faixa litorânea (linha de preamar). No segundo momento entrevistaram-se os proprietários intermediários ao mar e

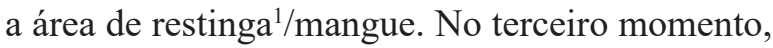

${ }^{1}$ Restinga corresponde à vegetação que ocorre adjacente ao oceano nas planícies costeiras arenosas (Amaral et al., 2008). 
entrevistaram-se os localizados mais afastados do mar e mais próximos das áreas de preservação permanente (APP).

O total amostral foi de 115 entrevistas pessoais (Ajuruteua: 25 empresários e 15 moradores; Atalaia: 25 empresários e 15 moradores e, Crispim: 17 empresários e 18 moradores). As amostras foram definidas a partir do Censo do IBGE (2010), que isolou por setor a praia de Ajuruteua e a ilha do Atalaia. A praia do Crispim não foi isolada em setor censitário. O quantitativo das amostras ficou entre $25 \%$ a $35 \%$ a partir do total de domicílios ocupados permanentemente. Não se considerou o total de domicílios particulares, pois a maioria é ocupada temporariamente em períodos específicos do ano, dificultando a realização das entrevistas e a obtenção da representatividade. No entanto, entrevistaram-se os moradores permanentes e temporários (Tabela 1).

Optou-se em não entrevistar os visitantes, pois não se objetivava medir o seu grau de satisfação durante o seu tempo de permanência na praia. E sim, retratar o processo de uso e ocupação e, suas implicações socioeconômicas e ambientais a partir do conhecimento da população residente.
As questões foram definidas com perguntas fechadas buscando atender uma abordagem quantitativa, em virtude da complexidade e subjetividade do objeto de estudo. O questionário de entrevista foi padronizado abordando: o período de ocupação, a forma de aquisição do espaço, o ambiente natural existente durante aquisição, as áreas naturais evitadas, o trabalho empregado para preparar o ambiente para as construções, a orientação técnica durante o processo de ocupação, a motivação para aquisição do espaço em uso, as dificuldades enfrentadas pelos residentes e visitantes e, o nível de acessibilidade ao ambiente de praia. Na última etapa, os dados obtidos foram tabulados em planilha Excel e demonstrados na forma quantitativa (tabela).

\section{Resultados e discussão}

As análises e as discussões foram divididas em três tópicos, a partir da sequência dos resultados das entrevistas realizadas com os proprietários dos estabelecimentos comerciais e residenciais nas três áreas de estudo, referente ao processo de uso e ocupação e, suas implicações socioeconômicas e ambientais, apresentados na tabela 2 .

TABELA 1 - Amostra das entrevistas realizadas nas praias de Ajuruteua, Atalaia e Crispim, Estado do Pará, Brasil. Legenda: Pop. total: População total; Dom. part.: Domicílios particulares; Dom. ocup. perm.: Domicílios ocupados permanentes; Empr.: Empresário; Mor.: Morador.

\begin{tabular}{|c|c|c|c|c|c|c|c|c|c|c|}
\hline \multirow[b]{2}{*}{ Local } & \multicolumn{3}{|c|}{ Censo IBGE 2010} & \multicolumn{2}{|c|}{2013} & \multicolumn{2}{|c|}{2014} & \multicolumn{2}{|c|}{2015} & \multirow[b]{2}{*}{$\begin{array}{c}\text { Total por } \\
\text { praia }\end{array}$} \\
\hline & Pop. total & $\begin{array}{l}\text { Dom. } \\
\text { part. }\end{array}$ & $\begin{array}{l}\text { Dom. } \\
\text { ocup. } \\
\text { perm. }\end{array}$ & Empr. & Mor. & Empr. & Mor. & Empr. & Mor. & \\
\hline Ajuruteua & 588 & 423 & 154 & 20 & 2 & 4 & 5 & 1 & 8 & 40 \\
\hline Atalaia & 576 & 1.122 & 109 & 20 & 0 & 4 & 8 & 2 & 6 & 40 \\
\hline
\end{tabular}


TABELA 2 - Processo de ocupação e suas implicações atuais nas praias do Atalaia, Ajuruteua e Crispim Estado do Pará, Brasil.

Assuntos

Q.1) Período de aquisição do espaço em uso:

Atalaia

Ajuruteua

Crispim

$\%$

Década 1960

Década 1970

Década 1980

Década 1990

1

6

3

Década 2000

Década 2010

Q.2) Forma de aquisição do espaço em uso:

Cedido

Doado

Ocupado

Comprado

Alugado

\section{Q.3) Ambiente existente na aquisição:}

Cordões arenosos (dunas frontais a praia)

Dunas

Campo entre dunas (áreas baixas entre as dunas)

Mata de restinga

Mangue

Q.4) Áreas evitadas durante a aquisição:

Cordões arenosos

Dunas

Campos entre dunas

Mata de restinga

Mangue

Q.5) Trabalho empregado na área após aquisição:

Retirada das dunas

Limpeza

Aterramento

Desmatamento

Queimada

\section{Q)}

\section{Ausente}

Parcial

Integral

11

13

6

3

0

1

16

21

2

5
6
29
0
0

0
34
6
0
0

8

17

12

0

3

2

$\begin{array}{cc}0 & 0,9 \% \\ 0 & 7,8 \% \\ 3 & 16,5 \% \\ 7 & 25,2 \% \\ 19 & 37,4 \% \\ 6 & 12,2 \%\end{array}$

$12,2 \%$

$1,7 \%$

$4,3 \%$

$40,9 \%$

$47,0 \%$

$6,1 \%$

$3 \quad 6,1 \%$

2

$5,2 \%$

$21,7 \%$

$61,8 \%$

$0 \%$

$11,3 \%$

11

$7,8 \%$

$55,6 \%$

$17,4 \%$

$0,9 \%$

$18,3 \%$

$18 \quad 18,3 \%$


Q.7) Principal motivação de aquisição do espaço em uso:

\begin{tabular}{|c|c|c|c|c|}
\hline Residência & 4 & 11 & 4 & $16,50 \%$ \\
\hline $2^{\circ}$ Residência (casas de veraneio) & 0 & 1 & 19 & $17,40 \%$ \\
\hline Comércio/Serviços (alimentação, bebidas e hospedagem) & 36 & 28 & 12 & $66,10 \%$ \\
\hline Venda do imóvel & 0 & 0 & 0 & $0 \%$ \\
\hline Extrativismo animal (pesca/ captura mariscos e crustáceos) & 0 & 0 & 0 & $0 \%$ \\
\hline \multicolumn{5}{|c|}{ Q.8) Principal dificuldade enfrentada após a aquisição do espaço em uso: } \\
\hline Ausência de serviços públicos (Saneamento, segurança, saúde) & 30 & 19 & 34 & $72,30 \%$ \\
\hline Acessibilidade (meios de acesso a faixa de areia e banho) & 2 & 5 & 1 & $6,90 \%$ \\
\hline Especulação imobiliária & 0 & 0 & 0 & $0 \%$ \\
\hline Erosão costeira & 6 & 14 & 0 & $17,40 \%$ \\
\hline Baixo fluxo de visitantes & 2 & 0 & 0 & $1,70 \%$ \\
\hline Não informou & 0 & 2 & 0 & $1,70 \%$ \\
\hline \multicolumn{5}{|c|}{ Q.9) Principal dificuldade enfrentada pelo visitante, segundo a população local: } \\
\hline $\begin{array}{l}\text { Acessibilidade (transportes públicos e privados, vias de acesso, } \\
\text { acessibilidade a portadores de deficiência física, idosos e gestantes) }\end{array}$ & 3 & 11 & 2 & $13,90 \%$ \\
\hline Segurança & 3 & 1 & 1 & $4,30 \%$ \\
\hline Oferta de serviços (públicos e privados) & 5 & 13 & 13 & $27,00 \%$ \\
\hline Prestação de serviços (alimentação, bebidas, preço) & 29 & 12 & 19 & $52,20 \%$ \\
\hline Hospitalidade (tratamento dado ao visitante) & 0 & 3 & 0 & $2,60 \%$ \\
\hline \multicolumn{5}{|l|}{ Q.10) Nível de acessibilidade ao ambiente de praia (via rodoviária): } \\
\hline Péssimo & 4 & 18 & 0 & $19,10 \%$ \\
\hline Ruim & 1 & 3 & 0 & $3,50 \%$ \\
\hline Regular & 12 & 17 & 5 & $29,60 \%$ \\
\hline Bom & 19 & 1 & 18 & $33,00 \%$ \\
\hline Ótimo & 4 & 1 & 12 & $14,80 \%$ \\
\hline
\end{tabular}

O primeiro tópico corresponde as questões (Q) enumeradas de 1 a 7 da tabela, referente à formação socioespacial das áreas em estudo, a partir de 1960 , período em que a praia do Atalaia passa a receber as políticas públicas de desenvolvimento socioeconômico. O segundo corresponde as Q.8 a Q.10, que permitem sinalizar a situação atual ao tratar das implicações socioeconômicas e ambientais resultantes dos processos pretéritos de urbanização, turistificação e acessibilidade rodoviária.
O terceiro tópico atende ao objetivo deste estudo referente as principais mudanças ocorridas nos aspectos socioeconômicos e ambientais resultantes processo de uso e ocupação nas três praias, a partir de 1960, que exigem soluções e mitigações por parte do poder público, setor privado e comunidade local.

\subsection{O processo de ocupação e formação socioespacial}


Os resultados apresentados a seguir demonstram informações acerca do processo de ocupação e formação socioespacial. Para Milton Santos, a formação socioespacial tem por base o conceito marxiano de formação social e econômica (modo de produção), acrescida da dimensão espaço ao discurso da formação, conciliando o tempo e o espaço, pois os modos de produção inscrevem a história no tempo, enquanto as formações sociais inscrevem a sua história no espaço (Machado, 2016). Assim, a formação socioespacial compreende as transformações espaciais no decorrer do tempo de uma sociedade, a partir da sua produção social e econômica (Bastos \& Casaril, 2016).

Até 1966, o ambiente de praia da ilha do Atalaia era habitada e utilizada por pescadores artesanais e, frequentada por pequenos grupos de veranistas em busca de descanso, banho de sol e mar. Até 1987, na praia de Ajuruteua uma fazenda ocupava parte do ambiente de pós-praia, bem como, abrigava desde a década de 1970 um grupo de famílias que haviam migrado da Vila do Chavascal (praia vizinha) após terem perdidos suas moradias com o avanço do mar. Na praia do Crispim, antes de 1991, também habitavam pescadores artesanais em duas residências e dois ranchos de pesca.

Os resultados evidenciam que o período de aquisição do espaço em uso (Q.1) nos três ambientes de praia, considerando a década de 1960 como marco temporal, tem na década de 2000 o período com maior número de aquisições $(37,4 \%)$. Analisando individualmente, a praia de Ajuruteua tem na década de 1980 o período com maior número de aquisições (13 indivíduos, representando 32\%), em reflexo ao incentivo do poder público municipal a urbanização da praia. Enquanto as praias de Crispim e Atalaia tem, na década de 2000, o maior número de aquisições, referente a ampliação e revitalização das infraestruturas urbanas e de transportes (estacionamento para ônibus fretados e carros, iluminação pública, rampa de acesso de veículos na praia Atalaia, banheiros públicos, etc.), tendo como objetivo principal a melhoria da qualidade do destino turístico (Souza, 2014).

Sobre a forma de aquisição do espaço em uso (Q.2), a especulação imobiliária ocorrida nos três ambientes, em seus diferentes períodos, motivou o processo de venda dos imóveis, em que $47,0 \%$ dos entrevistados informaram ter comprado. Analisando individualmente, somente na praia de Ajuruteua, $55 \%$ dos entrevistados afirmaram ter ocupado o espaço em uso. No percentual geral, a aquisição por ocupação (40,9\%), contrapõe com uma minoria em que aquisição do espaço foi cedida (1,7\%). Apesar da ilha do Atalaia ser uma propriedade privada, em que a aquisição de espaço ocorre através da compra de lotes, na década de 1980 houve uma ocupação espontânea das terras pertencentes ao Sr. Modesto Rodrigues, o que explica $40 \%$ dos entrevistados afirmarem ter ocupado o espaço em uso.

Após a implantação da Estância Hidromineral (1966), os senhores Modesto da Encarnação Rodrigues e João Felício Abrahão solicitaram e obtiveram do ministro do Trabalho e Previdência Social Jarbas Passarinho o título de terra da ilha do Atalaia $^{2}$, dando início a sua urbanização através da venda lotes, abertura da estrada Salinas-Atalaia (atual PA-444), construção da ponte do Sampaio

\footnotetext{
${ }^{2}$ As terras da ilha do Atalaia foram aforadas considerando o Decreto Lei 9.760/1946, que dispõe sobre os bens e imóveis em terras da União e seus acrescidos, tendo prioridade quem as cultivasse (Almeida, 2017).
} 
sobre o rio Arapepó (1971/72), pavimentação asfáltica (1973), criação de gado e plantio de coco; a multinacional Coca-Cola, visando expandir seu mercado na região, construiu 25 barracas na praia do Atalaia e sorteou entre os moradores da cidade (Almeida, 2017).

Esse processo de desenvolvimento urbano está em conformidade com o estudo de Zeng et al. (2016), ao afirmar que nas décadas passadas ocorreu uma expansão urbana generalizada nos países em desenvolvimento, ocupações humanas e rodovias espalharam-se rapidamente, promovendo enorme pressão sobre os ecossistemas. Para Oliveira Neto (2013), os investimentos públicos em expansão e interligação rodoviária na região Norte durante o regime político militar visavam à estruturação e a inserção da região Amazônica na economia nacional, além de promover a integração nacional.

Para compreender o ambiente existente durante aquisição do espaço (Q.3), considerou-se a partir da subdivisão do sistema praial o trecho de pós-praia, limitado em direção ao mar pelo nível de maré alta (escarpa de praia) e, em direção ao continente por dunas costeiras de sedimentação de areia por ação das ondas (Souza Filho; El-Robrini, 1996). Nos três ambientes de pós-praia no litoral do NE paraense, é comum a presença do cordão arenoso ou duna frontal, dunas, campo entre dunas, seguido dos ambientes de mata de restinga e mangue (Braga et al., 2007; Mendes et al., 2013; Souza Filho, 2013). Para os entrevistados $(61,8 \%)$ o ambiente existente no momento da aquisição eram campos entre dunas, seguido de dunas (21,7\%). Somente no Crispim, o ambiente de mangue foi o segundo mais ocupado (31\%), depois do campo entre dunas.

Ainda sobre o ambiente existente no processo de aquisição, também buscou-se identificar quais áreas foram evitadas durante este processo (Q.4). Os resultados demonstraram que a área mais evitada foi o ambiente de dunas $(55,6 \%)$, seguido do mangue (18,3\%). Numa análise individualizada da praia do Crispim o ambiente de mangue foi o mais evitado (Q.4: 51\%) durante o processo de ocupação do espaço em uso. Nota-se que nas praias do Atalaia e Ajuruteua o campo entre dunas, como áreas evitadas, ocupou a segunda posição, correspondendo com os resultados dos entrevistados da questão anterior (áreas ocupadas), que ocuparam as áreas de dunas, ficando na segunda posição.

Nestes ambientes, houve a necessidade de preparar área para o uso e ocupação (Q.5), em que 94\% dos entrevistados afirmaram ter empregado o trabalho de limpeza, seguido do desmatamento $(4,3 \%)$ e retirada de dunas (uso de tratores para nivelamento da área) (1,7\%). Entre os 115 entrevistados, nenhum afirmou ter utilizado a queimada e o aterramento como técnicas de trabalho para o uso e ocupação.

Quanto à orientação técnica ou fiscalização ambiental durante o processo de aquisição (Q.6), referente às áreas ocupadas e evitadas e, o tipo de trabalho empregado para o uso e ocupação, $90,5 \%$ afirmaram não ter recebido nenhum tipo de fiscalização e orientação baseada em princípios e normas técnicas estabelecidas por ordenamentos jurídicos ambientais, normas urbanísticas e planos de gerenciamento. Bem como nenhum tipo de proibição de compra e ocupação de lotes em APP (cordões arenosos, dunas e mangue) e penalidades por infração a tais normas, principalmente no período em que se iniciam os processos de urbanização e turistificação das praias balneares em estudo. Somente uma minoria dos proprietários comerciais e individuais, que compraram nas últimas décadas os imóveis 
em uso, afirmaram ter recebido de forma integral $(5,2 \%)$ e parcial $(4,3 \%)$ algum tipo de orientação e fiscalização ambiental.

Para compreender o processo de permissão para o uso e ocupação dos ambientes de pós-praia da ilha do Atalaia (1973), Ajuruteua (1987) e Crispim (1991), faz-se necessário verificar os parâmetros jurídicos ambientais e urbanísticos vigentes. Tomando como marco a década de 1960, tem-se o Código Florestal (Lei ${ }^{\circ}$ 4.771/1965), a lei do Uso e Parcelamento do Solo Urbano (Lei ${ }^{\circ}$ 6.776/1979), a Política Nacional de Meio Ambiente - PNMA (art. $18^{\circ}$ da Lei $\left.n^{\circ} 6.938 / 1981\right)$, a Resolução ${ }^{\circ} 004$ do CONAMA (1985), Plano Nacional de Gerenciamento Costeiro - PNGC (Lei ${ }^{\circ}$ 7.661/1988) ${ }^{3}$ (Sirvinskas, 2006). O disposto nestas leis e resoluções federais definem que a vegetação de restinga, que protegem as dunas e os manguezais, são áreas de preservação permanente - APP's, ou preservação ecológica, não podendo sofrer qualquer tipo de degradação ou retirada, bem como loteamento, construções e instalações que afetem a preservação e proteção da zona costeira e a qualidade de vida de sua população (Scherer et al., 2009).

Apesar da existência destes parâmetros jurídicos para preservação das APP's na zona costeira, em 1987, no âmbito do município de Bragança, o poder público municipal incentivou, através do discurso de promover o desenvolvimento socioeconômico a partir da atividade turística na praia de Ajuruteua, a sua urbanização sem considerar as normas jurídicas em vigor, atendendo aos interesses da elite política bragantina em transformar a praia em espaço de especulação imobiliária para obtenção de lucro
(Pereira et al., 2006; Fernandes et al., 2007; Alves, 2014).

Em 1988, no âmbito do município de Salinópolis, a Lei $n^{\circ} 2.075$ declarou a área da ilha do Atalaia como zona urbana, estabelecendo normas para a construção de imóveis no local (Dias, 1996). O legislador possuía como parâmetro jurídico a diretriz da PNMA, que determinava que os municípios poderiam elaborar leis, observadas as normas e padrões federais e estaduais relacionados ao meio ambiente (art. $6^{\circ} \S 2$ da Lei $n^{\circ} 6.938 / 1981$ ) (Sirvinskas, 2006). A lei municipal não poderia ter considerado a ilha do Atalaia em sua totalidade como zona urbana, deveria ter averiguado se toda área era viável para o parcelamento do solo, conforme a Lei $n^{\circ} 6.776 / 1979$, pois a mesma abriga APP's com manguezais, dunas e vegetação de restinga.

A Constituição Federal de 1988 permitiu um avanço no tratamento das questões urbanísticas e ambientais, ampliou a autonomia política, administrativa e financeira do município e delegou a competência da Câmara Municipal em elaborar a sua própria Lei Orgânica (art. 29²), legislar sobre assuntos de interesse local (art. $30^{\circ}$ ) e, aprovar o seu Plano Diretor como instrumento básico da política de desenvolvimento e expansão urbana (art. 182) (Brasil, 2016). A Constituição do Estado do Pará (1989) reconheceu a autonomia municipal (art. 51 ${ }^{\circ}$ ), passando a não legislar sobre o mesmo (Pará, 2011).

Na década de 1990, os municípios de Salinópolis e Marapanim aprovaram suas Leis Orgânicas Municipais, buscando compatibilizar o desenvolvimento socioeconômico com a preservação ambiental, prevendo a elaboração do Plano Diretor para

\footnotetext{
${ }^{3}$ No Pará o gerenciamento da zona costeira estadual foi previsto em 1995, através da Política Estadual de Meio Ambiente do Estado do Pará (Titulo V, Capitulo II, art. $72^{\circ}$ da Lei $n^{\circ}$ 5.887) (Szlafsztein, 2009). Porém o Projeto de Lei que institui a Política Estadual de Gerenciamento Costeiro está em tramitação.
} 
o desenvolvimento do planejamento urbano. Em Marapanim, a Lei Orgânica previu diretrizes para ocupação ou construção em ambientes de praia (art. 176, Parágrafo Único); no entanto, em 1991, após a inauguração da PA-318, o poder público não controlou e fiscalizou o uso e ocupação para fins comerciais e residências sobre as APP's, nem colaborou com o Instituto Brasileiro do Meio Ambiente e dos Recursos Naturais Renováveis - IBAMA(1989) na preservação do meio ambiente municipal (art. 172 ${ }^{\circ}$, inciso V, $\S 7^{\circ}$ ) (Marapanim, 1997).

Juridicamente não era permitido construir, modificar, ocupar mangues e dunas na orla marítima, sujeito a penalidade e multa por degradação ambiental. No entanto, os legisladores municipais de Salinópolis, Bragança e Crispim visaram o desenvolvimento socioeconômico em detrimento aos ordenamentos jurídicos de preservação das APP's. Estes se expandiram sem parâmetros urbanísticos, seus planos diretores somente foram aprovados em 2006, a exemplo de Bragança (Lei n. ${ }^{\circ}$ 3.875) e Salinópolis (Lei $\mathrm{n}^{\circ}$ 2.791). Assim, muitas obras irregulares, do ponto de vista ambiental e urbanístico, não teriam sido iniciadas no ambiente de pós-praia da ilha do Atalaia, Ajuruteua e Crispim, (Pará: 2006a; 2006b).

O processo de aquisição para uso e ocupação do ambiente de pós-praia tem relação direta com a motivação (Q.7), que para os entrevistados referem-se à implantação de comércios e oferta de serviço $(66,1 \%)$, seguido de $2^{\circ}$ residência $(17,4 \%)$ e residência permanente $(16,5 \%)$. Numa análise individualizada da praia do Crispim, a principal motivação está relacionada com segunda residência para veraneio (54\%). De todos os 115 entrevistados, nenhum informou como motivação a aquisição para venda do imóvel $(0 \%)$ e para trabalhar com extrativismo animal $(0 \%)$.

Para Pereira (2015), a ascensão dos valores industriais da civilização ocidental redefiniu a percepção da praia de um território vazio para um espaço social potencial à urbanização, atendendo às necessidades de lazer e bem-estar; assim a sociedade urbana passou a tratar a praia como um espaço privilegiado para estadia temporária de lazer, a exemplo da praia de Brighton (Inglaterra), que no século XIX foi à primeira praia urbanizada moderna formada a partir da procura da elite britânica, que passou a servir de modelo para a reinvenção do uso urbano das zonas costeiras do Mediterrâneo e da Flórida (USA).

O processo de ocupação urbana é um dos principais fatores de mudanças da orla marítima mundial. Em Portugal, a conjugação dos grandes ciclos migratórios na década de 1960 com a popularização de uma cultura recreativa balnear moderna, gerou condições para um processo acelerado de ocupação intensiva do litoral da região do Algarve (Pires et al., 2012). Nas décadas seguintes intensificaram-se desordenadamente as infraestruturas de apoio no litoral português, desqualificando a oferta, promovendo o abandono de atividades tradicionais, alterando significativamente a paisagem, com a transformação de pequenas vilas de pescadores em áreas densamente construídas, onde com frequência no verão se ultrapassa a capacidade de carga (Schmidt et al., 2012).

No Brasil, a partir da década de 1960, o turismo emerge como uma atividade econômica relevante, praticada principalmente pela classe média, em virtude da valorização do lazer, aumento do poder aquisitivo e do tempo livre. Assim, a busca 
pelo segmento turístico de "sol e praia" e a urbanização destes espaços, imputou um novo cenário no litoral brasileiro que, por não estar preparado para lidar com os seus efeitos, provocaram mudanças no litoral brasileiro (Quaresma \& Campos, 2006; Souza, 2009).

\subsection{As implicações socioeconômicas e ambientais na atualidade}

Os resultados a seguir demonstram as implicações socioeconômicas e ambientais resultantes das políticas desenvolvimentistas pretéritas nas áreas de habitação, atividade turística e infraestrutura rodoviária.

A principal dificuldade enfrentada após aquisição do espaço (Q.8) refere-se à ausência de serviços públicos $(72,3 \%)$, principalmente na área de saneamento básico. Em análise individualizada, na praia do Crispim a ausência de serviço de saneamento, saúde, educação, transporte público, etc., são as principais dificuldades enfrentadas pelos entrevistados na atualidade (97\%). Enquanto na praia de Ajuruteua a erosão costeira ocupa a segunda posição referente as dificuldades enfrentadas pelos moradores $(30 \%)$. Nos três locais, não foram registrados problemas relacionados com especulação imobiliária ( $0 \%)$.

Estes resultados corroboram com os estudos de Pereira et al. (2006), Furtado (2011) e Souza (2014), reafirmando a ausência da esfera pública na região, referente ao planejamento habitacional, implantação da infraestrutura urbana e de apoio ao turismo balnear. O poder público incentivou o uso e ocupação destes locais. Em seguida abandonou-os sem prover, principalmente, saneamento básico, motivando a abertura de poços, fossas sépticas e lançamento de água servida e resíduos sólidos sem tratamento, que provocaram poluição e contaminação do lençol freático e do solo. Segundo Cristiano et al. (2016), a falta de planejamento associado à proliferação de áreas balneares criaram uma ocupação inadequada do litoral brasileiro, com sérios prejuízos ambientais.

Para Rosa et al. (2016), ausência de serviços públicos infraestruturais urbanos acarreta problemas para a saúde humana, ordenamento territorial e economia local, além de alterar o meio ambiente e intensificar a emissão de resíduos. Marques et al. (2012), afirma que o aumento demográfico em áreas urbanizadas sem serviços públicos de saneamento reflete no aumento dos resíduos sólidos e na sua eliminação inadequada, provocando a contaminação do solo, ar e águas superficiais e subterrâneas, resultando na contaminação ambiental. Para Paiva \& Souza (2018) a falta de saneamento ambiental adequado é tida como uma das principais causas da poluição e da contaminação das águas para o abastecimento humano, contribuindo para os casos de doenças de veiculação hídrica.

A erosão costeira também é mencionada como a segunda maior dificuldade enfrentada pelos moradores e empresários. Em costa arenosas, são esperados que ocorram mudanças na posição do litoral (erosão ou acreção) em resposta a variações no nível do mar, balanço de sedimentos e condições hidrodinâmicas (Lira et al., 2016). A artificialização da zona costeira, por adensamento de ocupações urbanas e infraestruturas, provoca o desiquilíbrio do meio físico (Pires et al., 2012). A busca pelo reequilíbrio nem sempre é favorável à presença humana, provocando acidentes e desastres por erosão costeira (Parizzi, 2014). 
Desse embate entre as ações naturais e atividades antrópicas na linha de costa, a erosão costeira tornou-se um fenômeno global, demandando obras de proteção costeira dos mais variados tipos e funções (Medeiros et al., 2014). No litoral Centro de Portugal, obras têm contribuído para mitigar os impactos, exigindo grandes custos de investimentos e manutenção (Roebeling et al., 2011). No Reino Unido, a solução encontrada para a praia de Colwyn Bay (costa Norte do País de Gales) foi a realimentação artificial da praia com sedimentos (Oliveira et al., 2012). No continente Africano, nos trechos mais críticos do litoral da cidade de Maputo (Moçambique), foram instaladas várias estruturas longitudinais aderentes de proteção da ação do mar, além da alimentação artificial de sedimentos (Langa, 2007).

No Brasil, cerca de $35 \%$ da costa está sob efeito erosivo (Neves \& Muehe, 2008). No litoral do NE do Pará, os processos erosivos registrados em 2001 na praia de Ajuruteua provocaram perda de ruas, residências e estabelecimentos comerciais (Souza Filho, 2013). Neste mesmo ano na praia do Crispim, cerca de 18 edificações foram destruídas e danificadas parcialmente pelas marés de sizígias. Em 2015, marés de sizígias na praia de Ajuruteua provocaram destruição das edificações construídas na orla marítima (Almeida, 2015). No Atalaia, o avanço do mar sobre as mansões e barracas está forçando os proprietários de imóveis a reconstruírem a cada ano suas edificações (Ranieri \& El-Robrini, 2015).

As obras de proteção costeira de forma emergencial, sem critérios técnicos de engenharia, promovem consequências para o trecho do litoral em que foi implantada, comprometendo as atividades turísticas, lazer e moradia (Neves \& Muehe, 2008;
Pereira \& Coelho, 2013). No litoral paraense, a ausência de qualquer obra ou técnica de proteção costeira por parte do poder público tem agravado o avanço do mar sobre o continente.

As obras de defesa costeira em sistema de praia-duna demandam altos custos para a sua implantação e geram consequências ao trecho do litoral em que for implantado, por ser uma estrutura estática e rígida num meio dinâmico. Uma das técnicas de proteção costeira de baixo custo, que tem auxiliado na recuperação do campo de dunas, funcionando como barreira natural de proteção da ação do mar é o uso de paliçadas sobre dunas, que junto com o plantio da vegetação fixadora de sedimentos tem auxiliado na retenção dos sedimentos na deriva litorânea, promovendo a sua recuperação. Esta técnica já apresentou resultados positivos em trecho do litoral no sul do Brasil, no Uruguai e no litoral Centro de Portugal (Tabajara \& Weschenfelder, 2011; Almeida, 2014; Gutiérrez et al., 2015).

Outra técnica considerada exitosa e de baixo custo são as estruturas de geossintéticos (sacos e tubos de geotêxtil preenchidos com areia da praia), que funcionam como proteção ao dissipar a ação energética do mar, contendo o seu avanço sem transferir o processo erosivo para áreas adjacentes. Além da recuperação e estabilização da praia, a estrutura do geotêxtil pode ser utilizada na construção de dunas artificiais, aproveitando a disponibilidade de sedimentos existentes (Oh \& Shin, 2006; Saathoff et al., 2007; Koffler et al., 2008; Corbella \& Stretch, 2012).

Quanto ao turismo balnear, as principais dificuldades enfrentadas pelos visitantes (Q.9) referem-se à prestação de serviços de alimentação $(52,2 \%)$, relacionados à qualidade e preço dos alimentos e bebidas em oferta. Seguido da oferta de serviços 
públicos e privados (27\%), como a ausência de banheiros públicos e chuveiros. As condições de acessibilidade das pessoas nos transportes públicos e privados, bem como o acesso ao ambiente de praia por pessoas com deficiência motora ou com dificuldades de locomoção representou a terceira dificuldade dos usuários da praia (13,9\%).

Os resultados demonstram que não houve um planejamento do turismo balnear pelo poder público em suas diferentes esferas, contribuindo na atualidade para a oferta de serviços públicos e privados com deficiência, dificultando a eficiência da atividade turística. Bem como, a ausência da gestão integrada entre a urbanização e a atividade turística pelo Estado. Para Bombana et al. (2016), a gestão de praias urbanas visa minimizar os efeitos negativos das diversas atividades existentes e maximizar os benefícios do seu valor singular; no entanto, em muitos municípios costeiros a gestão está centrada basicamente na limpeza e primeiros socorros, com baixos recursos direcionado a sua gestão; a governança costeira deve ser realizado pelo Estado, setor privado e sociedade civil, porém as vezes não é assumida por nenhum departamento específico da administração pública.

Para Botero \& Hurtado (2009), as principais variáveis do gerenciamento de praias balneares são: a capacidade de carga, a percepção ambiental dos usuários (lixo, qualidade da água, infraestrutura de lazer, etc.), a classificação do tipo de praia, as funções da praia (uso recreativo, proteção da costa e reservatório ecológico), o ambiente externo (ciclos naturais, estrutura legal, política e, as atividades econômicas); desse modo, um gerenciamento costeiro integrado, que objetiva o desenvolvimento sustentável, garantiria a integridade dos ecossiste- mas, a equidade social e a eficiência econômica da atividade turística.

Quanto ao nível de acesso por via rodoviária (Q.10) até os ambientes de praia, considerando a manutenção da via pelo Estado, a maioria respondeu, em termos gerais, que o nível é bom (33\%), principalmente os entrevistados nas praias do Crispim e Atalaia. Enquanto para os entrevistados na praia de Ajuruteua ficou entre péssimo (45\%) e regular (42\%) o estado de conservação da rodovia (PA-458). A mesma estava em processo de recuperação das pontes e pavimentação asfáltica.

Atualmente, a mobilidade está cada vez mais presente nas políticas e estratégias territoriais e urbanas, pois impactam significativamente na vida das pessoas (Mello \& Portugal, 2017). Historicamente, o transporte de pessoas e de carga tem sido altamente relevante para o desenvolvimento econômico e social, refletindo diretamente a evolução de como a sociedade está organizada (Neuenfeldt Júnior et al., 2016). No entanto, o nível de acesso é um condicionante do uso e ocupação, por facilitar o acesso maior do fluxo de pessoas, moradias e atividades econômicas, sendo considerado um dos fatores motivadores para o aumento da pressão antrópica sobre os ecossistemas (Silva et al., 2008; Piatto \& Polette, 2012).

\subsection{As principais mudanças socioeconômicas e ambientais}

$\mathrm{O}$ resultado das entrevistas referente à forma de aquisição do espaço em uso (Q.2 - comprado: 47\%; ocupado: 40,9\%) e a motivação (Q.7 - comércio e serviços: $66,10 \%$ ), denotam que houve 
especulação imobiliária. Dentre os 115 entrevistados, nenhum informou ter como motivação exercer atividades pesqueiras ou de captura de mariscos e crustáceos (Q.7 - extrativismo animal: 0\%). Também não foram encontrados nas praias em estudo grupos de pescadores artesanais com seus instrumentos de pesca (embarcações, rede de pesca, linhas, armadilhas, rancho, curral, artefatos, etc.) e estratégias para a subsistência e reprodução social. Corroborando uma mudança social dos espaços de pesca para urbanização balnear, conforme mencionados nos estudos de Pereira et al. (2006), Furtado (2011), Mendes et al., (2013), Alves (2014).

A aquisição motivada para fins comerciais e prestação de serviços de alimentação e hospedagem, bem como, para casa de veraneio (Q.7 - $2^{\circ}$ residência: $17,4 \%$ ), também promoveram mudanças nas atividades econômicas através da substituição das atividades de pesca tradicionais para atividades turísticas. Estando em conformidade com os estudos de Adrião (2006), Quaresma \& Campos (2006), Furtado (2011).

Os dados referentes ao ambiente existente (Q.3 - campo entre dunas: 61,8\%) e evitado durante a aquisição (Q.4 - dunas: 55,6\%) e, o trabalho empregado (Q.5 - limpeza: 94\%), contribuíram para ocupação desordenada do ambiente de pós-praia que somado a ausência de orientação e fiscalização ambiental (Q.6 - ausente: 90,5\%) pelo poder público municipal e demais órgãos competentes, em cumprimento aos ordenamentos jurídicos de proteção da orla marítima, promoveram como mudança ambiental a perda da vegetação (mangue e restinga) e dunas para a instalação de edificações civis, conforme mencionado por Bastos et al. (2013), Mendes et al. (2013), Souza Filho (2013).
Essas principais mudanças socioeconômicas e ambientais também promoveram impactos sistematicamente entre os aspectos ambientais, econômicos e sociais, considerando que qualquer mudança num dos aspectos afeta mutuamente os demais. Estes são percebidos na atualidade e podem se intensificar caso o poder público, o setor privado e a comunidade local não reúnam esforços na tentativa de mitigar tais efeitos.

No ambiental, a perda da vegetação restinga impacta diretamente na fixação e proteção das dunas, a vegetação existente sobre as dunas frontais (na linha de preamar) possibilitam que estas funcionem como barreira natural de proteção dos ventos e da ação energética das ondas (Almeida, 2014). Sua ausência promoveu mudanças no perfil de praia por erosão costeira, forçando a população buscar novos espaços para uso e ocupação, podendo levar a novas perdas de vegetação e dunas, ameaçando a biodiversidade terrestre e marinha. A erosão costeira também provoca prejuízos nas atividades socioeconômicas, gerando a perda do valor paisagístico e imobiliário (impacto estético), comprometendo o potencial turístico local e aumentando a demanda de gastos públicos com obras de recuperação das áreas degradadas pela erosão da linha de costa (Medeiros et al., 2014).

No social, a ausência de serviços públicos como o saneamento básico motivou a abertura de poços e o uso excessivo de água do subsolo e subterrânea, reduzindo a disponibilidade de água doce para o consumo humano e aumentando a intrusão salina nos aquíferos (Mendes et al., 2013). Ausência de um sistema de coleta e tratamento de esgoto tem contribuído para contaminação do lençol freático (águas servidas e fossas) e aumento de doenças de 
vinculação hídrica (Almeida, 2017). As falhas no sistema de coleta de resíduos sólidos têm gerado seu acumulo em APP's, corpos d'água e no mar (Souza Filho, 2013).

No econômico, a ausência de serviços públi$\cos$, infraestrutura de apoio e planejamento tem afetado as atividades relacionadas ao turismo balnear, em virtude da sazonalidade turística (alta e baixa temporada), com concentração de veranistas no mês de julho (férias escolares) e feriados prolongados, que contribuem para a desqualificação da oferta e da prestação de serviços, diminuindo a eficiência econômica da atividade turística (Almeida, 2017).

\section{Conclusões}

A abordagem dos principais acontecimentos que contribuíram para a formação socioespacial das praias do Atalaia, Ajuruteua e Crispim no litoral do Nordeste do Pará, foram apresentados por meio de uma linha do tempo, que permitiu desenvolver uma discussão a partir da implantação das políticas públicas para o desenvolvimento socioeconômico da região, em consonância com o modelo desenvolvimentistas do governo brasileiro na segunda metade do século XX.

O litoral e as comunidades pesqueiras, por não estarem preparados para receber os efeitos dos investimentos em infraestrutura rodoviária, urbanização e turismo balnear, sofreram mudanças em seus aspectos. No ambiental houve a substituição da vegetação e dunas para edificações civis (Q.3 - campos entre dunas: 61,8\%; dunas: $21,7 \%$; mangue: 11,3\%; Q.7 - comércio/serviços: $66,1 \%$; $2^{\circ}$ residência: $17,40 \%$; residência: $16,5 \%$ ). No social, houve a substituição espaços de pesca para urbanização turística (Q.2 - comprado: 47\% e ocupado: 40,9\%). No econômico houve a substituição das atividades de pesca tradicional para atividade turística (Q.7 - comércio/serviços: 66,1\% e extrativismo animal: $0 \%$ ).

A forma como esses investimentos foram implantados promoveu consequências que são percebidos na atualidade como situações problemáticas, em que se destacam a falta de serviços públicos (Q.8 - ausência de serviços públicos: 72,3\%), recuo da linha de costa (Q.8 - erosão costeira: 17,4\%) e, a má qualidade da prestação dos serviços de apoio à atividade turística (Q.9 - prestação de serviços: 52,2\%; oferta de serviços: $27 \%$ ).

Conclui-se que as situações problemáticas atuais (poluição ambiental, erosão costeira, deficiência da oferta e serviços turísticos, etc.) são consequências do processo de ocupação e formação socioespacial desenvolvida pelo poder público, que para gerar o desenvolvimento socioeconômico desconsiderou os ordenamentos jurídicos de preservação da orla marítima, promovendo a expansão urbana e o desenvolvimento do turismo balnear, sem planejamento e infraestrutura adequada, gerando impactos negativos que dificultam o desenvolvimento socioeconômico da região.

Para minimizar esses efeitos negativos, o poder público deve direcionar ações nas áreas de meio ambiente, infraestrutura urbana, transportes e turismo, com base em estudos técnicos, ações emergenciais mitigadoras, normatização e fiscalização do uso e ocupação do espaço, através de um gerenciamento costeiro integrado entre o poder público, setor privado e comunidade local. 


\section{Agradecimentos}

Os autores agradecem à Coordenação de Aperfeiçoamento de Pessoal de Nível Superior (CAPES) pela concessão da bolsa de doutorado e, da bolsa do Programa de Doutorado Sanduíche no Exterior (Centro de Estudos de Geografia e Ordenamento de Território - CEGOT, Universidade de Coimbra, Portugal).

\section{Referências}

Adrião, D. Pescadores de sonhos: um olhar sobre as mudanças nas relações de trabalho e na organização social entre as famílias dos pescadores diante do veraneio e do turismo balnear em Salinópolis, Pará. Boletim do Museu Paraense Emílio Goeldi. Ciências Humanas, 1(2), 11-21, 2006. Disponível em: http://www.scielo.br/pdf/bgoeldi/ v1n2/v1n2a02.pdf

Almeida, A. C. Dinâmicas dunares no litoral centro de Portugal. In: Cunha, L.; Jacinto, R. (Org.). Paisagens e dinâmicas territoriais em Portugal e no Brasil, p.191-204, 2014.

Almeida, A. F. Amazônia atlântica: mudanças e impactos nas praias oceânicas paraenses. In: Vieira, I. C. G., Jardim, M. A. G.; Rocha, E. J. P. Amazônia em Tempo: estudos climáticos e socioambientais. Série Amazônia em Tempo. Belém: UFPA, MPEG, EMBRAPA, p. 337-355, 2015.

Almeida, A. F. Uso e ocupação do litoral amazônico: os efeitos socioeconômicos e ambientais. In: Vasconcelos, S. S.; Ruivo, M. L. P.; Lima, A. M. M. (Org.). Amazônia em tempo: impactos do uso da terra em diferentes escalas. Belém: UFPA, MPEG, EMBRAPA, 167-183, 2017.

Alves, A. B. Estrada Bragança-Ajuruteua e a percepção dos trabalhadores do manguezal paraense (1975-1991). A Palavrada, 5, 26-38, 2014. Disponível em: https://revistaapalavrada.files.wordpress.com/2014/07/alexandredebrito.pdf

Amaral, D. D.; Prost, M. T.; Bastos, M. N. C.; Costa Neto, S. V.; Santos, J. U. M. Restingas do litoral amazônico, estados do Pará, Amapá, Brasil. Boletim do Museu Paraense Emílio Goeldi. Ciências Naturais, 3(1), 35-67, 2008. Disponível em: scielo.iec.gov.br/scielo.php?script $=$ sci_arttex\&pi$\mathrm{d}=$ S1981_81142008000100003

Arend, M.; Fonseca, P. C. D. Brasil (1955-2005): 25 anos de catching up, 25 anos de falling behind. Revista de Economia Política, 32(1), 33-54, 2012. Disponível em: http://www. scielo.br/pdf/rep/v32n1/03.pdf

Bastos, J. M.; Casaril, C. C. A formação sócio-espacial como categoria de análise aos estudos sobre rede urbana: ampliando a discussão teórica. Geosul, 31(62), 271-298, 2016. Disponível em: https://periódicos.ufsc.br/index.php/ Geosul/article

Bastos, M. N. C.; Santos, J. U. M.; Amaral, D. D.; Costa Neto, S. V. Alterações ambientais de origem natural e antrópica na vegetação litorânea do Nordeste do Pará. In: Prost, M. T. R. C.; Mendes, A. Ecossistemas costeiros: impactos e gestão ambiental. Belém: MPEG, p. 25-34, 2013.

Becker, K. B. Um futuro para Amazônia. Série inventando o futuro. São Paulo: Oficina de Textos, 2008.

Becker, K. B. Amazônia: geopolítica na virada do III milênio. Rio de Janeiro: Garamond, 2009.

Bombana, B.; Conde, D.; Polette, M. Gestión de playas urbanas: un análisis comparativo de los procesos de gobernanza en las playas Pocitos (Montevideo, Uruguay) y Central (Balneário Camboriú -SC, Brasil). Desenvolvimento e Meio Ambiente, 36, 291-313, 2016. doi: 10.5380/ dma.v36i0.43858

Botero, C.; Hurtado, Y. Tourist beach sorts as a classification tool for integrated beach management in Latin America. Coastline Reports, 13, 133-142, 2009. Disponível em: http://databases.eucc-d.de/files/documents/00000888_Botero\&Hurtado.pdf

Braga, F. P. S.; Souza Filho, P. W. M.; Alves, M. A. M. S.; Pereira, L. C. C. Morfologia e sedimentologia da praia de macromaré de Ajuruteua, Amazônia, Norte do Brasil. Boletim Paranaense de Geociências, 60-61, 11-30, 2007. Disponível em: http://revistas.ufpr.br/geociencias/article/ view/5637

Brasil. Constituição da República Federativa do Brasil: 
texto constitucional promulgado em 5 de outubro de 1988, com as alterações determinadas pelas Emendas Constitucionais de Revisão nos 1 a 6/94, pelas Emendas Constitucionais $\mathrm{n}^{\text {os }} 1 / 92$ a 91/2016 e pelo Decreto Legislativo $n^{\circ} 186 / 2008$. Brasília: Senado Federal, Coordenação de Edições Técnicas, 2016.

Corbella, S.; Stretch, D. D. Coastal defences on the KwaZulu-Natal coast of South Africa: a review with particular reference to geotextiles. Journal of the South African Institution of Civil Engineering, 54(2), 55-64, 2012. Disponível em: http://www.scielo.org.za/scielo.php?script=sci_arttext\&pi$\mathrm{d}=\mathrm{S} 1021-20192012000200006$

Costa Neto, S. V.; Santos, J. U. M.; Bastos, M. N. C.; Amaral. D. D.; Lobato, L. C. B. Composição florística das formações herbáceas da restinga do Crispim, Marapanim, Pará. Boletim do Museu Paraense Emílio Goeldi. Sér, Bot., 16(2), 163-209, 2000. Disponível em: http://repositorio. museu-goeldi.br/handle/mgoeldi/693

Cristiano, S. C.; Rocketta, G. C.; Portzb, L. C.; Anfusoc, G.; Gruberb, N. L. S.; Williamse, A. T. Evaluation of coastal scenery in urban beaches: Torres, Rio Grande do Sul, Brazil. Revista de Gestão Costeira Integrada, 16(1), 1-78, 2016. doi: 10.5894/rgci661

Dias, D. M. S. Propriedade privada, política urbana e meio ambiente: considerações jurídicas sobre a ilha do Atalaia, no município de Salinópolis, Estado do Pará. $1^{\circ}$ ed. Série: Estudos do Numa. Belém: UFPA, NUMA, 1996.

Fernandes, M. E. B.; Fernandes, J. S.; Muriel-Cunha, J.; Sedovim, W. R.; Gomes, I. A.; Santana, D. S.; Sampaio, D. S.; Andrade, F. A. G.; Oliveira, F. P.; Brabo, L. B; Junior, M. G. S.; Elias, M. P. Efeito da construção da Rodovia PA458 sobre as florestas de mangue da península bragantina, Bragança, Pará, Brasil. UAKARI, 3(1), 55-63, 2007. doi: 10.31420/uacari.v3i1.19

Ferreira Penna, D. S. Breve notícia sobre os sambaquis do Pará. Archivos do Museu Nacional, 1, 85-99, 1876. Disponível em: http://www.museunacional.ufrj.br/obrasraras/o/ arq-mn_1/arq-mn_1-85-99.pdf

Furtado, L. F. G. Pesca artesanal: um delineamento de sua história no Pará. Boletim do Museu Paraense Emilio Goeldi, Série Antropologia, (79), 1-50, 1981. Disponível em: http:// repositorio.museu-goeldi.br/handle/mgoeldi/699

Furtado, L. F. G. Pesqueiros reais e pontos de pesca. Traços da territorialidade haliêutica ou pesqueira amazônica. Boletim do Museu Paraense Emílio Goeldi, Série Antropologia, 18(1), 3-26, 2002. Disponível em: http://repositorio. museu-goeldi.br/handle/mgoeldi/788

Furtado, L. F. G. Zona costeira amazônica: um espaço de reflexões teóricas e práticas sociais. In: Mendes, A. C.; Prost, M. T.; Castro, E. (Org.). Ecossistemas amazônicos: dinâmicas, impactos e valorização dos recursos naturais. Belém: MPEG, p.405-419, 2011.

Furtado, L. F. G. Ocupação humana do litoral amazônico. In: Prost, M. T. R. C.; Mendes, A. Ecossistemas costeiros: impactos e gestão ambiental. Belém: MPEG, 2013. 220p.

Furtado, L. F. G.; Nascimento, I. H.; Santana, G.; Maneschy, M. C. Formas de utilização de manguezais no litoral do Estado do Pará: casos de Marapanim e São Caetano de Odivelas. Amazônia: Ciência \& Desenvolvimento, 1(2), 113-127, 2006.

Gregório, A. M. S.; Mendes, A. C.; Busman, D. V. Erosão na praia do Atalaia: Salinópolis/PA. In: Mendes, A. C.; Prost, M. T.; Castro, E. (Org.). Ecossistemas amazônicos: dinâmicas, impactos e valorização dos recursos naturais. Belém: MPEG, p. 157-186, 2011.

Gutiérrez, O.; Panarioa, D.; Nagyb, G. J.; Piñeiroc, G.; Montes, C. Long-term morphological evolution of urban pocket beaches in Montevideo (Uruguay): impacts of coastal interventions and links to climate forcing. Revista de Gestão Costeira Integrada, 15(4), 467-484, 2015. doi: $10.5894 /$ rgci553

IBGE - Instituto Brasileiro de Geografia e Estatística. Sinopse do Censo Demográfico 2010. Unidades da Federação. Pará. Rio de Janeiro, 2010.

Kajihara, K. A imagem do Brasil no exterior: análise do material de divulgação oficial da EMBRATUR, desde 1966 até 2008. Observatório de Inovação do Turismo. Revista Acadêmica, 5(3), 2-30, 2010. Disponível em: http://bibliotecadigital.fgv.br/ojs/index.php/oit/article/viewFile/5777/4489

Koffler, A.; Choura, M.; Bendriss, A.; Zengerink, E. Geosynthetics in protection against erosion for river and coastal 
banks and marine and hydraulic construction. Journal of Coastal Conservation,12(1), 11-17, 2008. doi: 10.1007/ s11852-008-0023-x

Lakatos, E. M.; Marconi, M. A. Metodologia cientifica: ciência e conhecimento científico, métodos científicos, teoria, hipóteses, variáveis. 5 ed. rer. e ampl. São Paulo: Atlas, 2007.

Langa, J. V. Q. Problemas na zona costeira de Moçambique com ênfase para a costa de Maputo. Revista de Gestão Costeira Integrada, 7(1), 33-44, 2007. Disponível em: http:// www.aprh.pt/rgci/pdf/rgci-8_Langa.pdf

Lira, C. P.; Silva, A. N.; Taborda, R.; Andrad, C. F. Coastline evolution of Portuguese low-lying sandy coast in the last 50 years: an integrated approach. Earth System Science Data, 8, 265-278, 2016. doi: 10.5194/essd-8-265-2016.

Lohmann, G.; Panosso Netto, A. Teoria do turismo: conceitos, modelos e sistemas. São Paulo: Aleph, 2008. 486p.

Machado, T. A. A formação social em Marx à formação socioespacial em Milton Santos: uma categoria geográfica para interpretar o Brasil? GEOgraphia, 18(38), 71-98, 2016. doi: 10.22409/geographia.v18i38.1057

Marapanim. Lei Orgânica de Marapanim. Câmara municipal. Belém: CEJUP, 1997.

Marques, R. F. P. V.; Silva, A. M.; Rodrigues, L. S.; Coelho, G. Impacts of urban solid waste disposal on the quality of surface water in three cities of Minas Gerais - Brazil. Ciência e Agrotecnologia, 36(6), 684-692, 2012. Disponível em: http://www.scielo.br/pdf/cagro/v36n6/10.pdf

Medeiros, E. C. S.; Pantalena, A. F.; Miola, B.; Lima, R. S.; Soares, M. O. Percepção ambiental da erosão costeira em uma praia no litoral Nordeste do Brasil (Praia da Taíba, CE). Revista de Gestão Costeira Integrada, 14(3), 471-482, 2014. doi: $10.5894 /$ rgci488

Meirelles Filho, J. C. M. Livro de ouro da Amazônia. 5. ed. Rio de Janeiro: Ediouro, 2006.

Mello, A.; Portugal, L. Um procedimento baseado na acessibilidade para a concepção de Planos Estratégicos de Mobilidade Urbana: o caso do Brasil. Eure, 43(128), 99-125, 2017. doi: 10.4067/S0250-71612017000100005
Mendes, A. C.; Silva, M. S.; Santos, V. F. Análise do meio físico para gestão ambiental das ilhas de Algodoal e Atalaia (NE do Pará). In: Prost, M. T. R. C.; Mendes, A. Ecossistemas costeiros: impactos e gestão ambiental. Belém: MPEG, p. 103-111, 2013.

MMA - Ministério do Meio Ambiente. Diagnóstico para avaliação e ações prioritárias para conservação da biodiversidade da zona costeira e marinha amazônica. Santos, J. U. M.; Gorayeb, I. S.; Bastos, M. N. C. (Org.). Projeto de conservação e utilização sustentável da diversidade biológica brasileira. Belém: 1999. Disponível em: http:// www.anp.gov.br/brnd/round6/guias/PERFURACAO/PERFURACAO_R6/refere/RegiaoNorte.pdf.

Neuenfeldt Júnior, A. L.; Siluk, J. C. M.; Paris, S. R. The scientific research context of urban transport for bus rapid transit systems applications. Journal of Transport Literature, 10(4), 15-19, 2016. doi: http://dx.doi.org/10.1590/22381031.jtl.v10n4a3

Neves, C. F. Muehe, D. Vulnerabilidade, impactos e adaptações a mudanças do clima: a zona costeira. In: Parcerias e estratégias. Mudanças de clima no Brasil: vulnerabilidade, impactos e adaptação. (27), 217-295, 2008.

Oh, Y. I.; Shin, E. C. Using submerged geotextile tubes in the protection of the E. Korean shore. Costal Engineering, 53(11), 879-895, 2006. doi: 10.1016/j.coastaleng.2006.06.005

Oliveira Neto, T. Rodovia Transamazônica: falência de um grande projeto geopolítico. Revista Geonorte, Edição Especial, 3, 7(1), 282-298, 2013. Disponível em: http:// www.periodicos.ufam.edu.br/index.php/revista-geonorte/ article/viewFile/1166/1057

Oliveira, F. S. B. F.; Reis, M. T.; Freire, P.; Neves, M. G.; Sancho, F.; Silva, L. G.; Clímaco, M.; Vicente, C. M. Aplicação de modelação numérica e física para o estudo da reabilitação e proteção da praia de Colwyn Bay, País de Gales, Reino Unido. Revista de Gestão Costeira Integrada, 12(3), 323-342, 2012. Disponível em: http://www.aprh.pt/ $\mathrm{rgci} / \mathrm{rgci} 323 . \mathrm{html}$

Paiva, R. F. P. S.; Souza, M. F. P. Associação entre condições socioeconômicas, sanitárias e de atenção básica e a morbidade hospitalar por doenças de veiculação hídrica no 
Brasil. Cadernos de Saúde Pública, 34(1), 1-11, 2018. doi: 10.1590/0102-311X00017316.

Pará (Estado). Lei n. ${ }^{\circ}$ 3.875, de 10 de outubro de 2006. Dispõe sobre o Plano Diretor Participativo do Município de Bragança. Bragança: DOE de 10/10/2006a

Pará (Estado). Lei n ${ }^{\circ} 279$, de 28 de Setembro de 2006. Institui o Plano Diretor Participativo de Salinópolis. Salinópolis: DOE de 28/09/2006b

Pará (Estado). Constituição do Estado do Pará e Emendas Constitucionais 01 a 51, 14 de dezembro de 2011. Belém: DOE de 20/12/2011.

Parizzi, M. G. Desastres naturais e induzidos e o risco urbano. Geonomos, 22(1), 1-9, 2014. Disponível em: http:// www.igc.ufmg.br/portaldeperiodicos/index.php/geonomos/ article/view/288/251

Pereira, L. C. C.; Ribeiro, M. J. S.; Guimarães, D. O.; Souza Filho, P. W. M.; Costa, R. M. Formas de usos e ocupação na praia de Ajuruteua - Pará (Brasil). Desenvolvimento e Meio Ambiente, 13, 19-30, 2006. Disponível em: http://revistas. ufpr.br/made/article/view/4788

Pereira, A. Q. Urbanization-metropolization and holiday resorts on the northeast coast of Brazil. Mercator, 14(4), 107-121, 2015. doi: 10.4215/RM2015.1404. 0008

Pereira, C.; Coelho, C. Mapas de risco das zonas costeiras por efeito de ação energética do mar. Revista de Gestão Costeira Integrada, 13(1), 27-43, 2013. doi: 10.5894/rgci325

Piatto, L.; Polette, M. Análise do processo de artificialização do município de Balneário Camboriú, SC, Brasil. Revista de Gestão Costeira Integrada, 12(1), 77-88, 2012. Disponível em: http://www.aprh.pt/rgci/pdf/rgci-274_Piatto.pdf

Pinto, P. M. Políticas de turismo e sustentabilidade em comunidades tradicionais: perspectivas conceituais. Boletim do Museu Paraense Emílio Goeldi. Ciências Humanas, 2(1), 11-22, 2007. Disponível em: http://www.scielo.br/ pdf/bgoeldi/v2n1/v2n1a02.pdf

Pires, I; Craveiro, J.; Antunes, Ó. Artificialização do solo e vulnerabilidade humana em duas zonas sujeitas a processos de erosão costeira: casos de estudo da costa da Caparica e Espinho (Portugal). Revista de Gestão Costeira Integrada, 12(3), 277-290, 2012. Disponível em: http://www.aprh.pt/
rgci/pdf/rgci-316_Pires.pdf

Quaresma, H. D. A. B.; Campos, R. I. R. Turismo como instrumento de ação coletiva em áreas pesqueiras do litoral da Amazônia. Boletim do Museu Paraense Emílio Goeldi. Ciências Humanas, 1(2), 139-147, 2006. Disponível em: http://www.scielo.br/pdf/bgoeldi/v1n2/v1n2a11.pdf

Ranieri, L. A; El-Robrini, M. Evolução da linha de costa de Salinópolis, Nordeste do Pará, Brasil. Pesquisas em Geociências, 42(3), 207-226, 2015. Disponível em: http:// www.ufrgs.br/igeo/pesquisas/4203/014203.pdf

Ranieri, L. A; El-Robrini, M. Condição oceanográfica, uso e ocupação da costa de Salinópolis (Setor Corvina - Atalaia), Nordeste do Pará, Brasil. Revista de Gestão Costeira Integrada, 16(2), 133-146, 2016. doi: 10.5894/rgci565.

Roebeling, P. C; Coelho, C. D.; Reis, E. M. Coastal erosion and coastal defense interventions: a cost-benefit analysis. Journal of Coastal Research, 64, 415-1419. 2011.

Rosa, F. S.; Díaz-Becerra, O. A.; Lunkes, R. J. Saneamento básico: análise da relação entre gastos públicos e atendimento à população em cidades brasileiras e peruanas. Revista Cientifica General José María Córdova, 14(18), 195-213, 2016. Disponível em: http://www.scielo.org.co/pdf/recig/ v14n18/v14n18a11.pdf

Saathoff, F.; Oumeraci, H.; Restall, S. Australian and German experiences on the use of geotextile containers. Geotextiles and Geomembranes, 25(4-5): 251-263, 2007. doi: 10.1016/j.geotexmem.2007.02.009

Scherer, M.; Sanches, M.; Negreiros, D. H. Gestão das zonas costeiras e as políticas públicas no Brasil: um diagnóstico. Rede Iberoamericana de Manejo Costeiro (Brasil). Agencia Brasileira de Gerenciamento Costeiro. 2009. Disponível em: http://hum117.uca.es/ibermar/Resultados\%20y\%20 descargas/publicaciones/brasil

Schmidt, L.; Santos, F. D.; Prista, P.; Saraiva, T.; Gomes, C. Alterações climáticas, sociais e políticas em Portugal: processos de governança num litoral em risco. Ambiente \& Sociedade, 15(1), 23-40, 2012. Disponível em: http://www. scielo.br/pdf/asoc/v15n1/03.pdf

Silva, I. R.; Bittencourt, A. C. S. P.; Silva, S. B. M.; Dominguez, J. M. L.; Filho, J. R. S. Nível de antropização X 
nível de uso das praias de porto seguro (BA): subsídios para uma avaliação da capacidade de carga. Revista de Gestão Costeira Integrada, 8(1), 81-92, 2008. Disponível em: http://www.aprh.pt/rgci/rgci25.html

Silveira, M. I. Oliveira, E. R.; Kerni, D. C.; Costa, M. L.; Rodrigues, S.F.S. O sítio Jabuti, em Bragança, Pará, no cenário arqueológico do litoral amazônico. Boletim do Museu Paraense Emílio Goeldi. Ciências Humanas, 6(2), 335-345, 2011. Disponível em: www.scielo.br/pdf/bgoeldi/ v6n2/a06v6n2.pdf

Silveira, M. I.; Schaan, D. P. A vida nos manguezais: a ocupação humana da costa Atlântica Amazônica durante o Holoceno. In: Pereira, E. Guapindaia, V. (Org.). Arqueologia Amazônia 1. Belém: MPEG, IPHAN, SECULT, 2010. 2 v.

Simões, M. F. Coletores-pescadores ceramistas do litoral do Salgado (Pará). Boletim do Museu Paraense Emílio Goeldi. Nova Série: Antropologia, 78, 1-26, 1981. Disponível em: http://repositorio.museu-goeldi.br/bitstream/mgoeldi/719/1/ EIAA\%20cap.\%20Silveira\%20\%26\%Schann.pdf.

Sirvinskas, L. P. Legislação de direito ambiental. São Paulo: Rideel, 2006.

Souza Filho, P. W. M. Dinâmica natural e impactos antrópicos no uso das áreas costeiras da planície bragantina, nordeste do Pará, Brasil. In: Prost, M. T. R. C.; Mendes, A. Ecossistemas costeiros: impactos e gestão ambiental. Belém: MPEG, p. 131-144, 2013.
Souza Filho, P. W. M.; El-Robrini, M. Morfologia, processos de sedimentação e litofácies dos ambientes morfosedimentares da planície costeira bragantina, Nordeste do Pará (Brasil). Revista Geonomos, 4(1), 1-16, 1996. Disponível em: http://general.igc.ufmg.br/geonomon/ PDFs/4_2_01_16_SouzaFilho.pdf

Souza, C. R. G. A erosão costeira e os desafios da gestão costeira no Brasil. Revista de Gestão Costeira Integrada, 9(1), 17-37, 2009. Disponível em: http://www.aprh.pt/rgci/ pdf/rgci_7-1.pdf

Souza, D. L. Urbanização turística, políticas públicas e desenvolvimento: o caso de Salinópolis/PA. Geografia em Questão, 7(1), 65-86, 2014. Disponível em: http://e-revista. unioeste.br/index.php/geoemquestao/article/view/9443/0

Szlafsztein, C. F. Indefinições e obstáculos no gerenciamento da zona costeira do Estado do Pará, Brasil. Revista de Gestão Costeira Integrada, 9(2), 47-58, 2009. Disponível em: http://www.aprh.pt/rgci/issue9f2.html

Tabajara, L. L. C. A.; Weschenfelder, J. Recuperação de dunas frontais em área degrada por sangradouro na praia de Xangri-Lá, RS. GRAVEL, 9(1), 69-85, 2011. Disponível em: http://www.ufrgs.br/gravel/9/1/Gravel_9_V1_06.pdf

Zeng, C.; Deng, X.; Dong, J.; Hu. P. Urbanization and sustainability: comparison of the processes in "BIC" countries. Sustainability, 8(400), 1-18, 2016. Disponível em: http:// mdpi.com/2071-1050/8/4/400/pdf 